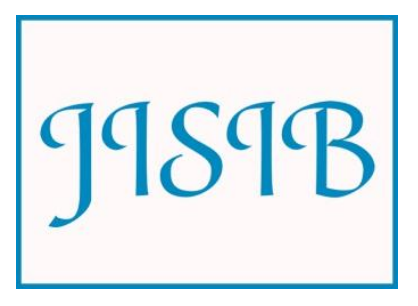

Available for free online at https://ojs.hh.se/

Journal of Intelligence Studies in Business 1 (2011) 87-96

\title{
Establishment and application of Competitive Intelligence System in Mobile Devices
}

\author{
Anass El Haddadi *,**, Bernard Dousset * and Ilham Berrada ** \\ * IRIT UMR 5505, University of Toulouse III \\ 118, Route de Narbonne, F-31062 Toulouse cedex 9, France \\ haddadi@irit.fr, dousset@irit.fr \\ ** ENSIAS, Al BIRONI Team, University of Med V-Souissi, \\ B.P. 713 Agdal - Rabat, Morocco \\ iberrada@ensias.ma
}

Received 25 May 2011; received in revised form 22 August 2011; accepted 11 December 2011

\begin{abstract}
The strategy concept has changed dramatically: from a long range planning to strategic planning then to strategic responsiveness. This response implies moving from a concept of change to a concept of continuous evolution. In our context, the competitive intelligence system presented aims to improve decision-making in all aspects of business life, particularly for offensive and innovative decisions. In the paper we present XPlor EveryWhere, our competitive intelligence system based on a multidimensional analysis model for mobile devices. The objective of this system is to capture the information environment in all dimensions of a decision problem, with the exploitation of information by analyzing the evolution of their interactions.
\end{abstract}

Keywords: Competitive Intelligence, competitive intelligence systems, XPlor EveryWhere, Business Intelligence, continuous evolution 


\section{Introduction}

Companies today are faced with external risk factors linked with an increased competition in markets that are extremely dynamic and unpredictable. This is caused by new competitors, mergers and acquisition, sharp price cuts, rapid changes in consumption patterns and weak brands. In this dynamical condition the competitive intelligence system (CIS) and Business Intelligence (BI) software becomes a main component when companies develop their strategies. Today information technology is considered as a simple support for organizations, but in a strategic way it promises to contribute to a sustainable competitive advantage.

For five decades the concept of a strategy has changed dramatically from being a long range planning tool to become strategic planning and thereafter ending up as strategic responsiveness. By embracing the responsiveness concept a company can be flexible and constantly evolve. A competitive intelligence system (Salles, 2002) aims to improve decision-making in all aspects of business life, in particular for offensive and innovative decisions.

To face all the challenges that appear in a dynamic industry, competitive intelligence platforms are designed to provide online services. Competitive Intelligence (CI) can be seen as both a process and a product (Haags, 2006). As a process, CI is the set of legal and ethical methods that a company uses to harness information that helps them to achieve international success. As a product, CI can be considered as an information system for analyzing data concerning competitors' activities collected from public and private sources, what is also referred to as Business Intelligence. The results of the analysis can provide knowledge regarding the current and future behavior of competitors, suppliers, customers, technologies, acquisitions, markets, products and services, and the general business environment. When collecting data for analysis sources as newspaper articles, corporate publications, websites, patent filings, specialized databases, information at trade shows and blogs can be used. The issue concerning $\mathrm{CI}$ is how to build a CIS (CI as a product) and model analysis (CI as a process).

Our contribution in this paper is to propose an information system adapted to the needs of a CI process. The system' $\mathrm{s}$ mission is to provide a methodological reference for collecting, treating and analyzing information. Also an analysis of the information environment in all of its dimensions will be made.

The rest of the paper is structured as follows: In section two we identify the analytical models of CI, with support from the Medesiie model and the Site model. In section three we explain information system adapted to the CI approach. Section four presents our multidimensional analysis model for CI and section five presents the architecture of a CIS.
Finally in section six a summary and evaluation of the method will be found.

\section{The analytical models of CI}

Through the different characteristics of CI, we identify four dimensions in the definition of an analytical model. The four dimensions are as follows:

1. The environmental dimension for a company which includes elements that may influence the strategy of a company. The environment is characterized by partners, competitors, markets and customers.

2. The human dimension which include those who are involved in the CI process, whether internal or external to the company. The human dimension is characterized by networks of collaboration, interaction and communication between different actors.

3. The strategic dimension corresponds to different models of analysis for the company, from identifying objectives to the decision and the definition of actions.

4. The technological dimension brings together all the methods, tools and techniques used in the CI process; Information retrieval, collection, treatment and dissemination of information.

The inclusion of one or more of these dimensions can result in various models used for the analysis (conceptual or practical) of CI. We selected two academic models built on these dimensions: Medesiie model and Site model.

\subsection{Medesiie model}

The Medesiie model is a method for defining a information system for CI. The CI approach proposed in the project Medesiie is devoted entirely to the needs analysis of Small and Medium-sized Enterprises (SME) in CI. Medesiie consider a CIS as a representation of the enterprise' $\mathrm{s}$ knowledge.

The conceptual architecture of this system is based on the definition given by Seligman, Wijers \& Sol (1989) regarding the design of CIS. Salles, 2003 describe a CIS with four components; The way of thinking, The way of modeling, The way of organizing and The way of supporting. Medesiie suggests a model to describe the company, its strategy, its environment, its needs under/within the CI and its products and services (Salles, 2003).

There are different types of models that the Medesiie model describes. It could be a business model, that is described according to its different functions, for example production, economy / market linkages, financial and innovation / information 
system. Each function is itself composed of a set of sub-management functions.

A strategic model is represented by a set of strategic choices and areas of development such as a search of independence and business growth. An environment model is described initially by the business functions and the relationships it develops in the environment. The surrounding context includes the spatial geometry of markets, technology, competition, the financial system, supply conditions, the regulatory framework, environmental policy and geopolitics. A model of needs provides a framework for the collection of requirements and their formalization, analysis and validation. The expressed needs are represented by a set of units' needed. The model unit requirement is described in terms of three dimensions. One, the control level of decisions for which the units are expressed (value: operational, tactical or strategic). Two, the phase of the decisionmaking process associated with the unit and three, its informational content (identification of its value and function). The last example of Medesiie' s models is a model of products/ services. Any supply of decision making bearing the environment of a company is a prototyping tool made according to the collected needs, the cost defined, reached and powered to evaluate the effects a priori.

\subsection{Site model}

The Site model includes different models of CI, proposed by the research team Site-Loria. These models are based on the linking of three spaces: the space of decision problems, the space of the informational problems and the space of mediations. The three spaces are connected through exchanges between the two types of actors, the decision-maker and the watchman.

Teamwork is important, thus the inclusion of the user in the information systems is important. They propose models to define the different actors, their interactions and their positioning in the CI process.

We have retained the following three models: EquAte (Explore Query Analysis annotated), MEPD (Model for the Explanation of a decision problem) and WISP (Watcher-Information-Search- Problem).

The EquAte model represents a situation of information retrieval which implies the following cognitive phases (David \& Thiery, 2002):

- Exploring the word of information

- Querying the information base

- Analysis of the information base

- Annotation based on individual preferences

The MEPD model defines different steps for a decision making problem that is based on (Bouaka, 2004):
- Modeling the decision making by its identity, personality traits, cognitive style and experience.

- Modeling the environment by the immediate environment with customers, providers and competitors and the global environment with for example social-, economical- and political aspects.

- Modeling of organization, by environment, its signal, the assumptions that the decision-maker can infer the detection of signals collected.

The WISP model, associated with the threedimensional MEPD, is incorporating the same point of views (Kislin, 2007). The three dimensions are as follows:

1. An analytical dimension that includes understanding the demand-stake-context, the definition of informational indicators, the operations of analysis and creation of knowledge can be achieved by studying the stored elements.

2. A methodological dimension is incorporated at two levels. The first level regards the skills of transaction of the decision problem in the information problem. The second level regards strategies by which the information is identified and knowledge is acquired.

3. An operational dimension to define the selection of an action plan and implement the various stages of resolution for the methodology associated with the model WISP.

\section{Information systems adapted to the CI approach}

For Romagni and Wild (1998) the definition of an information system adapted to the CI approach is an organized set of procedures, at any time, to give decision makers a representation of a company in its environment and market. The CI function provides information to assist in executive functions, management and decision-making. It must facilitate decisions to automate a number of actions or providing decision makers with the necessary information for decision-making. It must also coordinate the processing of information, store sustainably information and improve data processing the creation of information directly applicable for decision makers.

The majority of current information systems are inadequate to manage the dynamic markets. They are mostly designed for stable and controlled environments and are built on vertical and complex organizational patterns. These types of information systems do not meet the needs of a CI process. It is therefore essential to develop information system that enables organizations to better manage information and provide a base for coordination of actions between different actors. This coordination is supported by the following motivations: 
-The goals of the CI approach are interrelated and cannot be led separately

-The need for information sharing between different actors

-The sharing of knowledge gained during a process

-The organization of the company in a cross-

functional manner.
The coupling between the needs are identified in a process of $\mathrm{CI}$ which include different collaborative techniques from business intelligence such as workflow, groupware, data warehousing, data mining, text mining and visualization. This optimizes each step in CI process. (Figure 2). It summarizes all of these techniques for each step in the CI process. The collection phase is usually through the use of



Figure 1: Transaction from a hierarchical structure to a functional global information infrastructure

Due to the above mentioned motivations it' $s$ important to move from a vertical architecture of information systems to a cross-architecture which allows the information to reach the management overall.

The cross-architecture is based on a modular and scalable architecture structured around the projects of a company. The global information infrastructure will enable us to:

- $\quad$ Reduce the number of vertical coordination by reducing management layers

- Improve environmental monitoring

- Opening-up of cross-communication

- Achieve relationships based on complementary businesses, and

- make a better adaptation to market dynamics.

According to the report of Cigref "Competitive intelligence and strategy" (2004) a portal of information management is currently the best tool to implement the concept and the culture of CI through a network. This portal is built around a software solution called here $C I$. The advantages of this type of information system are:

- Project management monitoring

- Information sharing

- Custom-made interface

- Collection that is more accurate and targeted

- Processing, analysis, storage

- Dissemination databases, internet, search agents and search engine. The steps of processing can be supported by visualization tools, statistical analysis and data warehouses. The diffusion step may rely on for example push-pull agents and emails.

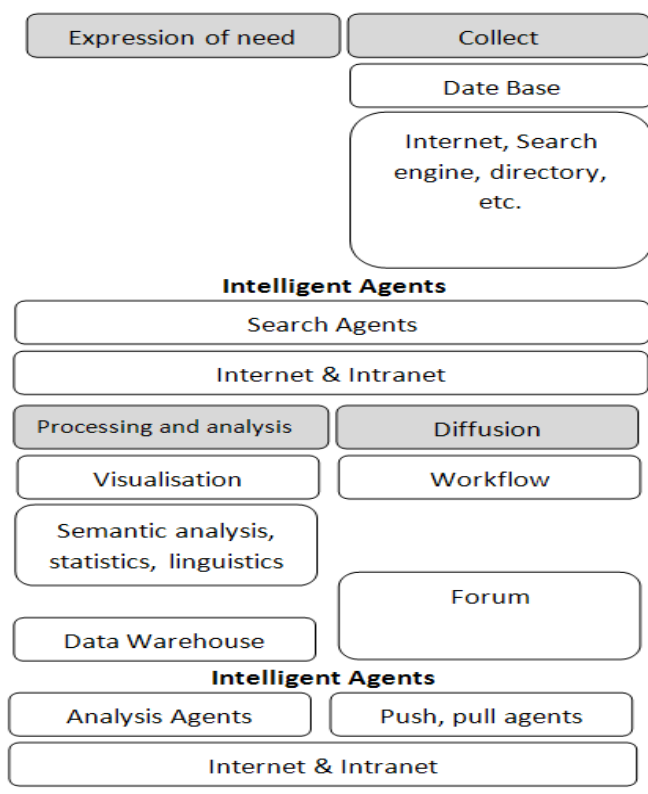

Figure 2: The various techniques of CI 


\section{Xplor: a multidimensional analysis model for CI}

Our contribution consists of a proposal for an information system adapted to the needs of a CI approach as define above. The objective of this system is to provide a reference methodology in order to collect, process and analyze information. Our system will observe and analyze the information of a decision problem in all dimensions. The approach combines two methods: Knowledge discovering in text (KDT) and environmental scanning.

\begin{tabular}{l}
\hline What $\quad$ Definition of the subject of analysis \\
\hline Why $\quad$ Identification of actors: Analysts, Experts, Watchmen, Makers \\
Who relevance of topics \\
When \\
Where \\
How \\
\hline
\end{tabular}

Table 1: Question 5W-1H (Ghalamallah, 2009)

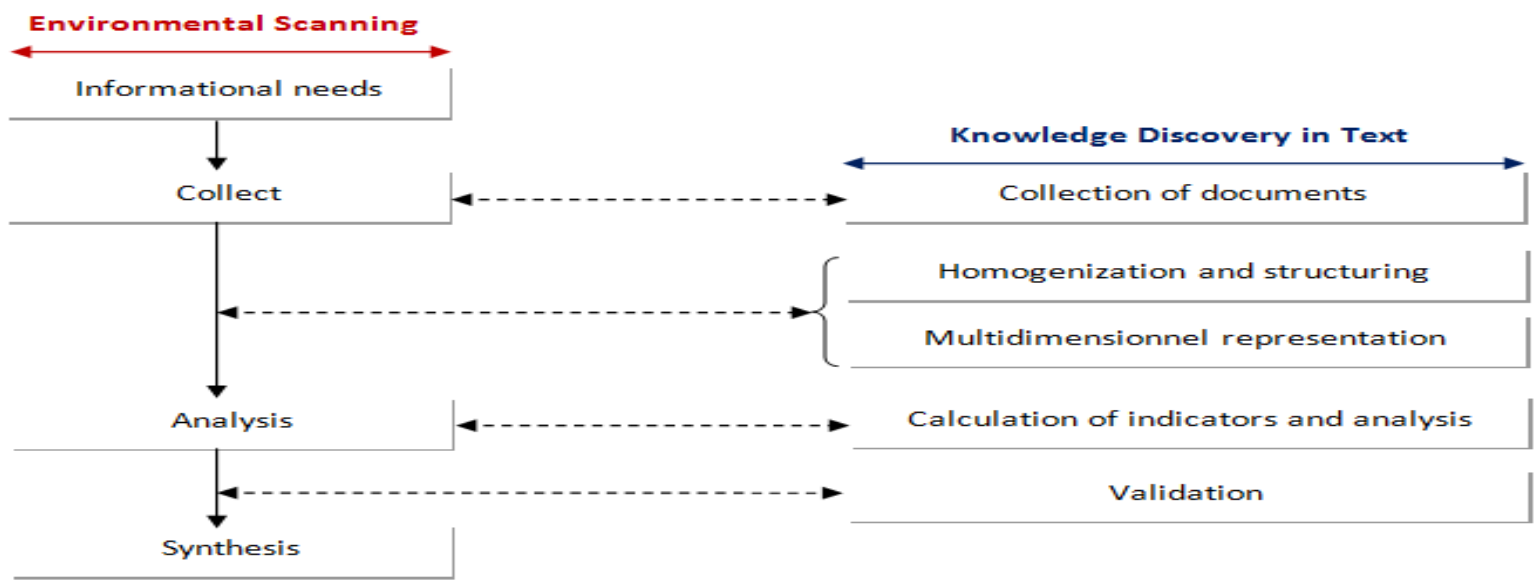

Figure 3: Coupling of Environmental scanning and KDT (Ghalamallah, 2009)

The model described is based on two main models:

1. A multidimensional representation of documents which can transfer qualitative data into quantitative. The objective of this model is to get a unified view of the documents collected.

2. A function model which aims to provide a set of generic and combinatory functions to build a different kinds of indicators needed for analysis.

The CIS proposed should manage the sharing of information between the different actors involved. The objective is to define a space of communication and information dissemination to provide a platform for collaboration and cooperation between different stakeholders. For this we define a user model adapted to each user profile.

\subsection{Planning activity}

The first activity of the proposed processes is planning. It is established from the informational problem defined by the users. The objective of this activity is to describe the process of guiding analysis.
We define this step by the method $5 \mathrm{~W}-1 \mathrm{H}$ : "What, Why, Who, When, Where, How" . Jakobiak (2006) developed a systemic approach for the creation of a CI project based on the $5 \mathrm{~W}-1 \mathrm{H}$ method (Table 1). The principle of the $5 \mathrm{~W}-1 \mathrm{H}$ is based on following circumstances, the person, the fact, the place, the means and reasons, the manner and the time. In this way a company can provide a detailed analysis plan for the CI project.

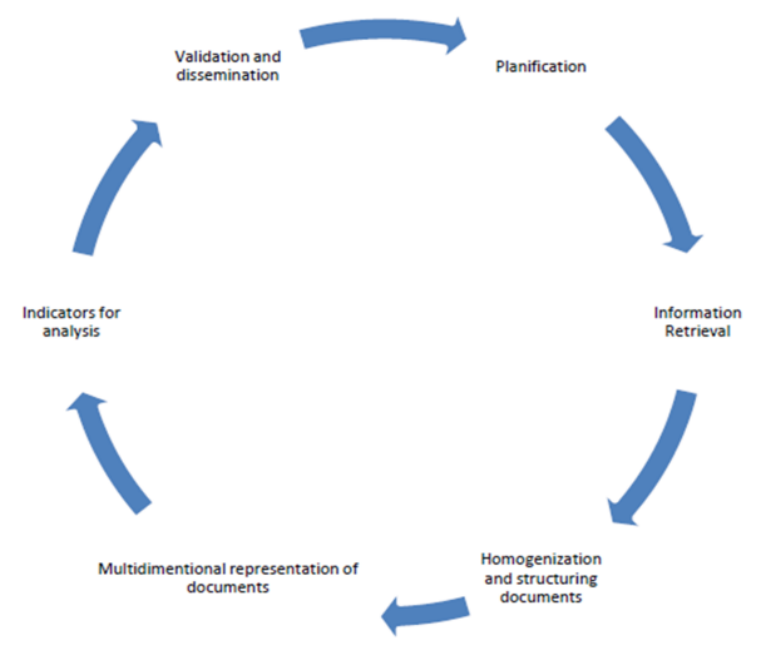

Figure 4 : Lifecycle of Xplor model 
We adapt this principle to describe the information needed and to guide the exploratory analysis. Originally, the proposal for the question How was to describe the procedures and actions to realize when the project is implemented. In the context of our process, the question How will describe the indicators to be implemented to meet the raised informational problems. The products of the planning steps are:

\begin{tabular}{|c|c|}
\hline What & The subject of analysis \\
\hline Why & The topics of the subject \\
\hline Who & Actors : Analysts, Experts, Watchmen, Makers \\
\hline When & Action planning \\
\hline Where & $\begin{array}{l}\text { Formal sources for each topic } \\
\text { Informal sources for each topic }\end{array}$ \\
\hline How & $\begin{array}{l}\text { Indicators for each topic } \\
\text { Target attributes, values, granularity and relationships for all } \\
\text { indicators }\end{array}$ \\
\hline
\end{tabular}

Table 2: The products of the planning step

In the planning phase an informational problem is described. This problem will be identified by the definition of its subject analysis. Once the subject is defined, the user must identify the themes of analysis, plan analysis operations and identify the involved actors. The validation of the themes of analysis leads the user to define two key activities for each topic, such as source of information and a definition of analysis indicators.

To enable an analysis, it' $s$ necessary to identify sources of information. The activity of indentifying consists in listing any formal and informal sources that may contain important information about the subject for the study (El Haddadi, Dousset, Berrada \& Loubier, 2010).

\subsection{Indicators for analysis}

The objective of this activity is to define indicators to be calculated and assessed. These indicators are intended to summarize and interpret the information environment of the analysis.

At this level of activity we must introduce the different indicators related to the theme. Each indicator was analyzed in order to identify target attributes, their granularity, their values and their relation. The aim of this decomposition is to clarify and describe the objects manipulated during processing to meet the indicator requirements. Each object of this decomposition will guide us through the various activities of the proposed process.
Once all sub-activities associated with the activity of planning are completed and validated, the results will be stored for later use.

We define an information need by grade of $N$ Where A need $\mathrm{N}$ is defined as follows:

$$
\mathbf{N}=\left\langle\mathrm{S}_{\mathrm{A}}, \operatorname{Obj}_{\mathrm{A}}, \operatorname{Ind}_{\mathrm{A}}, \operatorname{Act}_{\mathrm{A}}, \operatorname{Att}_{\mathrm{A}}\right\rangle
$$

$-S_{A}$ : is the overall context of the need for analysis $A$,

$-\mathrm{Obj}_{\mathrm{A}}=\left\langle\mathrm{Obj}_{1}, \mathrm{Obj}_{2}, \cdots, \mathrm{Obj}_{\mathrm{m}}\right\rangle$, represents the objectives set for the subject $S_{\mathrm{A}}$.

- Ind $_{\mathbf{A}}=\left\{\left\langle\right.\right.$ Obj $_{\mathbf{i}},<$ Indi $_{1}$, Indi $_{2}, \cdots$, Ind $\left._{\text {in }}>>\right\}$, represents the indicators associated with each objective.

$-\operatorname{Act}_{\mathrm{A}}=\left\{\left\langle\operatorname{Ind}_{\mathrm{ij}},\left\langle\operatorname{Act}_{\mathrm{ij} 1}, \operatorname{Act}_{\mathbf{i j} 2}, \cdots, \operatorname{Act}_{\mathbf{i j p}}\right\rangle>\right\}\right.$, represents the actors identified for indicators set for a goal.

$-\mathbf{A t t}_{\mathrm{A}}=\left\{<\mathbf{A c t}_{\mathbf{i j k}},<\mathbf{A t t}_{\mathbf{i j k} \mathbf{1}}, \mathbf{A t t}_{\mathbf{i j k} 2}, \cdots, \mathbf{A t t}_{\mathbf{i j k q}}\right.$ $>$ \}, represent the attributes specified each actors.

We define a hierarchy of concepts associated with the decomposition of indicators (Figure 5). Once all sub activities associated with the activity of planning are completed and validated, the result will be stored for later use.

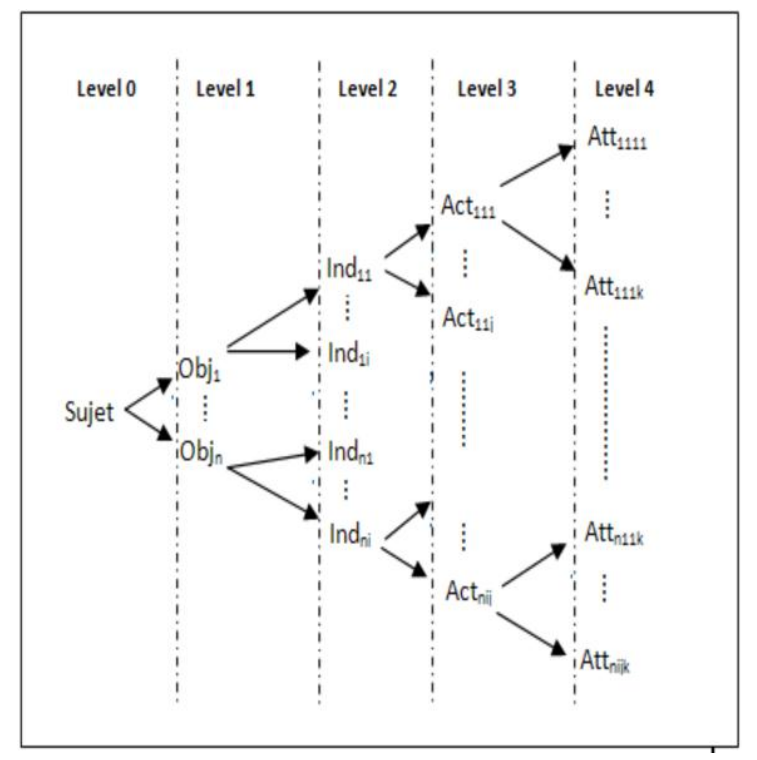

Figure 5: Hierarchy of concepts associated with the specification requirements

\subsection{Multidimensional representation of documents}

The objectives of this structure are to study the evolution of interactions between variables and make 
projections in the future which is essential for making strategic decisions.

Our proposal is to define a unique structure of intermediate data between raw information and knowledge derived in the form of a generic data warehouse. The multidimensional structure is based on a three dimensional modeling. This allows defining dependency relationships between different elements of the mining structured corpus, body of variables, with the inclusion of timing, that is the time variable (Figure 6).

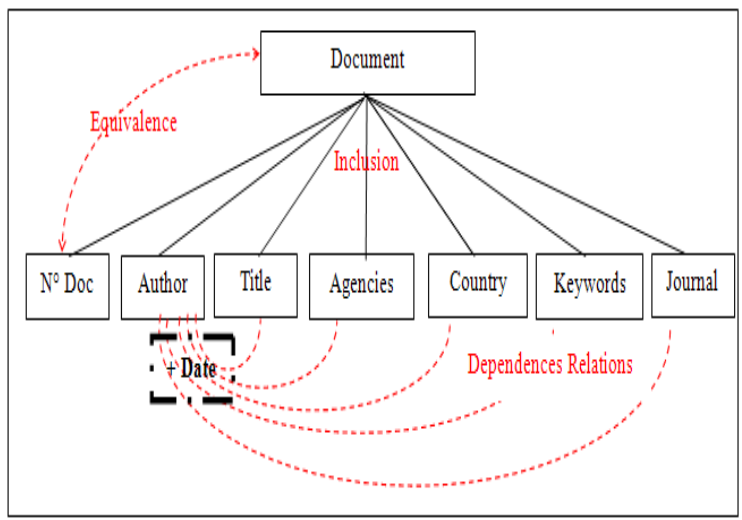

Figure 6: Example of dependency within threedimensional material and the temporal element

For a corpus of documents whose structure extraction is:

\section{StructureGlobal Extrac $=\left\langle N^{\circ}\right.$ Doc, Date, Author, Journal,Country, Keywords, Organism >}

We propose to build a three dimensional matrix which will define the dependency relationships that exist between the variables of the body by systematically incorporating the time variable.

Principle: Our goal is to identify the dependent relationships that exist in the body between the different variables of the study. These relationships are defined by a co-occurrence matrix. These matrixes indicate the simultaneous presence of the terms of two qualitative variables in a document. We adopt these matrixes by adding a third variable. The first two variables are qualitative associated with a multidimensional corpus.

The third variable is always the time associated with the corpus, for example date and year. Thus, the cooccurrence matrix is to indicate the presence of these three variables in a document (three-dimensional structure). We call this matrix a Cube.

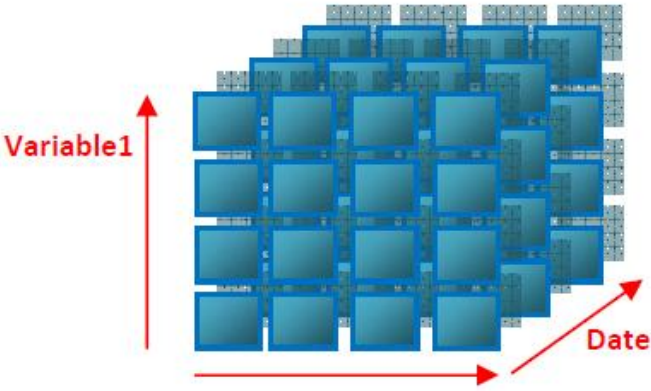

Variable 2

Figure 7: Data Cube

The Cube can describe existing relationships in a corpus period. We identify two types of Cubes:

1. A symmetric matrix: If we consider the simultaneous terms of a single variable and the time variable in a document the Cube becomes symmetric.

2. A asymmetrical matrix: Where we consider the presence of two distinct variables and the time variable in a document the Cube becomes asymmetric.

A corpus whose formal structure extraction is defined as:

$$
\begin{aligned}
& \text { Structure }_{\text {Global }}^{\text {Extrac }}=\quad<\quad \text { Chp }_{1 G}^{\text {Extrac }}, \quad \cdots, \\
& \text { Chp }_{i G^{\text {Exac }}}^{\text {Extra }}, \\
& \cdots, \text { Chp }_{j G}
\end{aligned}
$$

ChpiG $^{\text {Extrac }}$ corresponds to the element $i$ of the structure. We define the types of three-dimensional

\begin{tabular}{|c|c|c|c|c|c|}
\hline Dimensions & $\operatorname{Chp}_{16}{ }^{\text {Extrac }}$ & $\ldots$ & Chp $_{i c^{\text {Extrac }}}$ & $\ldots$ & $\operatorname{Chp}_{j 6}$ Extrac $^{\text {Ex }}$ \\
\hline $\operatorname{Chp}_{16^{\text {Extrac }}}$ & Symmetrical & $\ldots$ & Asymmetric & $\ldots$ & Asymmetric \\
\hline$\vdots$ & $\vdots$ & $\vdots$ & $\vdots$ & $\vdots$ & $\vdots$ \\
\hline $\operatorname{Chp}_{i G^{\text {Extrac }}}$ & Asymmetric & $\ldots$ & Symmetrical & $\ldots$ & Asymmetric \\
\hline$\vdots$ & $\vdots$ & $\vdots$ & $\vdots$ & $\vdots$ & $\vdots$ \\
\hline $\operatorname{Chp}_{j \mathrm{j}}{ }^{\text {Extrac }}$ & Asymmetric & $\ldots$ & Asymmetric & $\ldots$ & Symmetrical \\
\hline
\end{tabular}
matrixes between elements of the structure as in Table 3.

Table 3: Type of matrix 
We define the corpus associated with the multidimensional cube as:

The structure of the multidimensional corpus (3D)

$S C_{M 3 D}$ defined as:

$$
S C_{M 3 D}=\left\{\left\langle\operatorname{Dim}_{\mathrm{i}}, \operatorname{Dim}_{\mathrm{ij}}, \operatorname{Dim}_{\mathrm{T}}, \mathrm{Nb}_{\mathrm{Doc}}{ }^{\mathrm{ijT}}\right\rangle\right\}
$$

The multidimensional corpus $\boldsymbol{C}_{\boldsymbol{M} \mathbf{} \boldsymbol{} \boldsymbol{D}}$ defined as:

$$
C_{M 3 D}=\left\{\left\langle\operatorname{Att}_{\mathbf{x}}{ }_{\mathbf{i}}, \mathbf{A t t}_{\mathbf{y}}{ }^{\mathrm{ij}}, \mathbf{A t t}_{\mathbf{z}}{ }^{\mathbf{i j T}}, \mathbf{A t t}_{\mathbf{o}}{ }^{\mathrm{ijT}}\right\rangle\right\}
$$

With:

- $A t t_{x}{ }^{i} \in D_{i}$ the set of attributes $\left\{\mathrm{Att}_{1}{ }^{\mathrm{i}}, \cdots\right.$,

Att $\left._{\mathrm{p}}{ }^{\mathrm{i}}\right\}$ in Dimension $\mathrm{i}$ « Dimi »,

- $\mathrm{Att}_{\mathrm{y}}{ }_{\mathrm{ij}} \in D_{j}$ the set of attributes $\left\{\mathrm{Att}_{1}{ }^{\mathrm{j}}, \cdots\right.$,

$\left.\mathrm{Att}_{\mathrm{q}}{ }^{\mathrm{j}}\right\}$ in Dimension $\mathrm{j}$ associated with the dimension $\mathrm{I}$ i «Dim $\mathrm{Dij}_{\mathrm{ij}} »$,

- $\mathrm{Att}_{\mathrm{z}}{ }^{\mathrm{ijT}} \in D_{T}$ the set of attributes $\left\{\mathrm{Att}_{1}{ }^{\mathrm{T}}, \cdots\right.$,

$\left.\mathrm{Att}_{\mathrm{r}}^{\mathrm{T}}\right\}$ in Dimension time « $\operatorname{Dim}_{\mathrm{T}} »$,

- $\mathrm{Att}_{\mathrm{o}}{ }^{\mathrm{ijT}} \in N b_{D}$ the set of attributes $\left\{\mathrm{Att}_{1}{ }^{\mathrm{Nb}}, \cdots\right.$,

$\left.\mathrm{Att}_{\mathrm{l}}{ }^{\mathrm{Nb}}\right\}$ the number of documents in the three dimensions appear simultaneously.

$$
\begin{gathered}
\mathrm{Att}_{\mathrm{o}}{ }^{\mathrm{ijT}}=D_{i} \times D_{j} \times D_{T}\left[\mathrm{Att}_{\mathrm{x}}{ }^{\mathrm{i}}, \mathrm{Att}_{\mathrm{y}}{ }^{\mathrm{ij}}, \mathrm{Att}_{\mathrm{z}}{ }^{\mathrm{ijT}}\right] \text { et } \\
\mathrm{Att}_{\mathrm{o}}{ }^{\mathrm{jiT}}>=1
\end{gathered}
$$

\section{XPlor Everywhere : Competitive intelligence system for mobile}

Xplor EveryWhere is a CI platform that performs global strategic analysis on aggregate or factual entries from online bibliographic databases, CDRom, Internet or any other computerized source. Through descriptive and statistics exploratory methods of data, Xplor EveryWhere display in a very short time new strategic knowledge such as the identity of the actors, their reputation, their relationships, their sites of action, their mobility, emerging issues and concepts, terminology and promising fields.
1. Develop 2. Choose 3. Identify \& Prioritize 4. Identify
\& select 5. Collect \& Evaluate 6. Organize \& Remember 7.
Validate \& Stream 8. Analyze \& Interpret
9. Validate \& Spread

\subsection{System architecture}

As shown in figure 8 , strategic analysis and surveillance are the basic methodology of the process of Information Fusion in the Xplor CI platform. The architecture of our platform consists of four main services as shown in figure 9: 




Figure 9: Xplor Everywhere Architecture

1. Monitoring Service: A request is generated on a data source like a scientific database, patents database, RSS and blogs to collect data depending on client's needs. The collected data form the corpus.

2. Homogenization and structuring Service: Diversity of data sources leads to heterogeneous data, format and language must be restructured. At the end, this service defines a unified view of documents in the corpus.

3. Reporting Service: Reporting is the service responsible for presenting the analysis results to the decision-makers according to the push strategy with IPhone Service (El Haddadi, Dousset \& Berrada, 2010), SMS Service, and E-mail Service or pull strategy with Web Site Services.

4. Security Administration Service: Orthogonal to all three mentioned services, this Service controls data access and ensures the preservation of privacy during the treatments (Hatim, El Haddadi, El Bakkali, Dousset \& Berrada, 2010).

\subsection{Reporting service}

The reporting is the last, important service to be accomplished in the CI process. On this level we propose four types of services, the Phone Service, the SMS Service, the Web Site Service and the E-mail Service. With these different services, it is possible to access strategic information anywhere. In order to ease the navigability of the strategic information, we intend to integrate specific visualization techniques to each type of request like evolutionary histograms, geographical charts, social networks, profile networks, semantic networks and international networks (Figure 10):

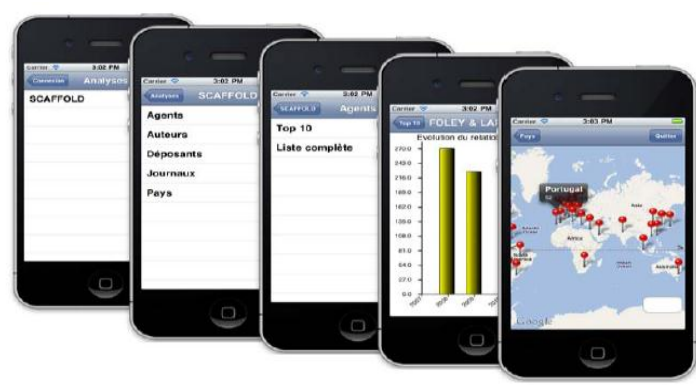

Figure 10: Reporting service of Xplor Everywhere

It is possible to navigate among three different types of networks. The social networks are based on relationships among the different authors, inventors, research teams, companies and the evolution of their relations. The semantic networks contain relationships among keywords in a domain and the evolution of research topics. The international networks are built on international collaboration between countries.

\section{Conclusion}

In this paper, we present a competitive intelligence system tool based on a multidimensional analysis model. A lot of strategic information comes from the relationship between and relevance of knowledge extracted, which often depends on consideration of data evolution and their interactions. In this paper we have defined a model for these relationship forms.

Our CIS is dedicated to cover all stages of discovery, extraction and data management: Without forgetting the criteria by which we get to handle any type of information, both formal and informal. With Xplor and Xplor EveryWhere, which are still mdeos but potentially soon to be commercialized, we completed an entire reporting service, including the aspect of mobility (smartphone application). With the system it' s possible to view updated information as we gain access to strategic database servers in realtime and daily feeds by observers. With this application it is now easy to enter information at trade shows, after customer visits or meetings.

Our plan for future studies is to continue our experiments on different types of relationships in order to propose a unified model to better generate and organize knowledge for companies. 


\section{References}

Bouaka, N. 2004. Développement d'un modèle pour l'explication d'un problème décisionnel : un outil d'aide à la décision dans un contexte d'Intelligence Economique. Thèse de doctorat de l'université Nancy 2.

El haddadi, A., Dousset, B., Berrada, I., \& Loubier, I. 2010. Les multi-sources dans un contexte d'Intelligence Economique, EGC, P A1-125 A1136.

El haddadi, Dousset, B., \& Berrada, I. 2010. Xplor everywhere - a tool for competitive intelligence on the web and mobile, VSST. 25-29 Octobre, Toulouse France.

David, A. \& Thiery, O. 2002. Application of "EQuA2te" Architecture. Economic Intelligence.

Ghalamallah, I.. 2009. Proposition d'un modèle d'analyse exploratoire multidimensionnelle dans un contexte d'intelligence economique, doctorat de l'université de toulouse, 18 décembre.

Gilad, B. 2008. The Future of Competitive Intelligence, Contest for the Profession's Soul, Competitive Intelligence Magazine, 11(5), 22.

Haags, S. 2006. Management Information Systems for the Information Age, McGraw-Hill Ryerson.

Hatim, H., El haddadi, A., El bakkali, H., Dousset, B. \& Berrada, I. 2010. "Approche générique de contrôle d'accés aux donénes et aux traitements dans une plate-forme d'intelligence économique", colloque Veille Stratégique et technologique.

Jakobiak, F. 2006. L'intelligence économique: la comprendre, l'implanter, l'utiliser. Les éditions d'organisation.

Kislin, P.H. 2007. Modélisation du problème informationnel du veilleur dans la démarche d'intelligence économique. Thèse de doctorat de l'université Nancy 2, France.

Rapport Cigref. 2004. Club Informatique des Grandes Entreprises Françaises, Intelligence économique et stratégique. Rapport Cigref.

Romagni, P., Wild, V. 1998. L'Intelligence économique au service de l'entreprise, ou l'information comme outil de gestion. Les Presses du Management.

Salles, M. 2002a. Projet MEDESIIE : Méthode MEDESIIE de définition du besoin en intelligence économique des PME, Touluse: Université Toulouse I.

Salles, M. 2003b. Modélisation des situations de décision dans une méthode d'ingénierie du besoin en I.E, Conférence IERA, Intelligence Economique : Recherches et Applications, Nancy, France.

Salles, M. 2005c. De l'analyse du besoin des PME en IE à l'Intelligence Territoriale. Colloque Européen d'Intelligence Economique, Poitiers Futuroscope, ESCEM Poitiers, p. 414-427, Poitiers, France.
Seligman P.S., Wijers G.M., Sol H.G. 1989. Analyzing the structure of I.S. methodologies, an alternative approach, In proceedings of the Conference in information systems, The Netherlands.

Vedder R. G., Vanecek M. T., Guynes C. S. and Cappel J. J. 1999. CEO and CIO Perspectives on Competitive Intelligence, Communications of the $A C M, 42,8$. 